\title{
O TEATRO TROPISMAL de Nathalie Sarraute
}

Renato de Mello UFMG

\begin{abstract}
RESUMO
Este texto tem por objetivo o estudo do teatro de Nathalie Sarraute no qual se analisam dois aspectos singulares de sua escrita: a presença de sujeitos fragmentados, expondose numa estrutura dramática, e a busca do re-sentido daquilo que ela nomeou de tropismos.

\section{PALAVRAS-CHAVE}

teatro, Nathalie Sarraute, tropismos, Nouveau Roman
\end{abstract}

Falar sobre Nathalie Sarraute e suas peças teatrais obriga-nos a tratar, ainda que superficialmente, do Nouveau Roman. Para alguns, o Nouveau Roman não existe e nunca existiu, tendo sido apenas um modismo passageiro, praticado por um grupo de fanáticos doutrinários. Outros dizem que o Nouveau Roman não constitui uma escola porque não há regras comuns, reuniões sistemáticas, um manifesto, um programa comum e, portanto, não deve ser considerado como escola. Ainda outros aproxinam, sem nenhuma restrição, escritores como Claude Simon, Alain Robbe-Grillet, Nathalie Sarraute, a partir de um ponto comum a todos: o rompimento com a tradição literária ocidental. ${ }^{1}$

Os nouveaux romanciers não só se aliaram aos modernistas de vanguarda contra as técnicas da literatura realista mas também os renovaram. Enquanto os modernistas, recusando a representação dos realistas, lutavam contra a falta de referente real para poder criar a ilusão da verdade, os nouveaux romanciers, ao contrário, privilegiaram e questionaram a linguagem, trabalhando no nível da anti-representação. Diferentemente da representação e da auto-representaçāo, não há nenhum plano fixo na anti-representação, seja interior, seja exterior. As próprias açōes não se fixam. Mesmo quando una cena se repete, essa repetição não garante um plano fixo. É exatamente ela que gera a instabilidade textual, porque o leitor/espectador năo adquire certeza sobre o que se passou. A incerteza, geralmente, é produzida pela mudança de ponto de vista pelo qual a cena é apresentada, ou pela manutenção do ponto de vista em uma personagem minada pela dúvida em relação ao que aconteceu. $O$ resultado é um texto que vai em todas as direçōes. ${ }^{2}$ Porém, se na auto-representação e na anti-representação

\footnotetext{
' Refiro-me, aqui, a vários críticos que tentam compreender o fenômeno do Nouveau Roman, cf. GOLDMAN, Pour une sociologie du roman; ALBÈRES, Le roman d'aujourd'hui; JANVIER, Une parole exigeante; MAURIAC, L'alittérature comtemporaine; RicardoU, Problèmes du Nouveau Roman, Nouveau Roman, Pour une théorie du Nouveau Roman.

${ }^{2}$ A respeito da anti-representação Cf. RuCARDou. Nouveau roman, tel quel, p.433-454.
} 
o espaço da ficção torna-se plural, o que as diferenciam é que, na primeira, tal pluralidade dá-se por profusão das semelhanças, e, na segunda, por multiplicação das diferenças. Na anti-representação, ainda nos termos de Jean Ricardou, não se trata de exprimir ou de representar algo que já existia; trata-se de produzir algo que ainda não existe. ${ }^{3}$ Os nouveaux romanciers substituíram o universo significativo dos realistas e dos modernistas por um universo onde as coisas e os acontecimentos existem e sāo apresentados antes mesmo de significar. $O$ texto cria-se então quase que sozinho, do desdobrar imprevisível das possibilidades do real. ${ }^{4}$ Com isso, os nouveaux romanciers transformaram-se em pesquisadores desconfiados, procurando algo que ainda não fora explorado e dito.

A ruptura com a representação foi marcada pela recusa da intriga tradicional, da personagem psicológica, da análise dos sentimentos, da literatura engajada e do eu objetivado. Sentindo a necessidade de renovar as formas antigas, os modernistas utilizavam-se da auto-representação e o texto deixou de ser um espelho do mundo para ser um efeito de espelhos: o texto abandona o referente externo para dobrar-se sobre si mesmo. No interior da obra, algo se repete para mostrar a semelhança. Ao invés de ser a imagem de um mundo exterior, o texto torna-se a instância de desdobramentos de seus próprios elementos. É a partir de si mesmo que o texto prolifera. ${ }^{5}$

Nathalie Sarraute escreveu 6 peças de teatro: Le silence e Le mensonge (1967), Isma (1970), Elle est là (1975), C'est beau (1978) e Pour un oui et pour un non (1982). Seis peças e sempre a mesma problemática: a palavra que conduz a açāo dramática. A linguagem não sugere nada além daquilo que as personagens sentem, já que a linguagem e o que elas sentem é a mesma coisa, ou seja, tudo o que elas sentem é o que elas dizem, não havendo nada fora da linguagem. A linguagem se torna, assim, perigosa, fascinante e especular. Não há intriga. Tudo começa com uma palavra, uma frase, uma forma de pronunciá-la ou, às vezes, até mesmo o silêncio. As palavras desencadeiam, ao longo das peças, reaçōes cada vez mais violentas, levando as personagens a zonas perigosas, a movimentos interiores, delicados, onde o diálogo camufla enquanto se revela.

As obras dramáticas de Nathalie Sarraute nos propõem a destruição total do "teatro". Suas peças são construídas a partir de um detalhe - insignificante para a maioria - uma espécie de provocação que leva a um movimento ou efeito de algo ressentido que dá às palavras uma força de propulsão, uma carga de sentidos, uma linguagem impulsiva. É importante também como o texto é dito, a entonação. O que Sarraute quer é concentrar-se sobre a palavra e não sobre os gestos das personagens, com seu lado comum e realista.

Sarraute propõe a destruição do teatro porque verificou-se que o material trabalhado contém algo de completamente desconhecido e novo para o público e até mesmo para os atores e diretores de teatro: os tropismos, uma realidade psíquica que será utilizada para designar, inicialmente, movimentos interiores da vida subterrânea das personagens. Esses tropismos são, geralmente, fugidios, instáveis, fugazes, passageiros, impossíveis de ser explicados, podendo apenas ser capturados e revividos. Toda

\footnotetext{
${ }^{3}$ RICARDOU. Pour une théorie du nouveau roman, p.261.

${ }^{4}$ PERrone-Molsés. O novo romance francês, p. 19.

${ }^{5} \mathrm{C}$. Ricardou. Nouveau roman, tel quel, p.452-454.
} 
a sua obra é marcada pelo desejo de mostrar que, no momento em que se tem a impressão de que absolutamente nada acontece, é que se vê, através de um microscópio ou em câmera lenta, que coisas vivas aparecem: os tropismos. ${ }^{6}$

Uma palavra é dita e eis que se desencadeiam os tropismos. As personagens de Isma, tentando compreender a origem do mal-estar que os Dubuit provocam nos outros, imitam a maneira como eles pronunciam as palavras terminadas em -isma, e brincam, de uma certa forma, colocando-se no lugar deles:

Ela: Escute: romantisma. Capitalisma. Sindicalisma...ma...ma....isso estoura...isso faz estalar os lábios...

Ele: Isso é saboroso...mm, é bom. Isma...Isma...Isma....?

A cena torna-se o lugar de um ritual mágico onde as palavras pronunciadas são encarregadas de caçar os demônios acordados pelos espasmos tropísmicos. Trata-se de, através do viés deste jogo da palavra, da vibração da voz, anular os efeitos de uma palavra anterior, de restituir ao verbo uma forma de autenticidade e de positividade que sua natureza tendia, no princípio, privá-lo. Sarraute diz que é a linguagem a responsável pela ação, que é da linguagem que tudo começa.

mais estranho é que as personagens de Sarraute não têm controle sobre os movimentos tropismais. Eles the são inevitáveis a ponto de enviá-las ao seu caráter profundamente trágico. Percebe-se que o tema ou o assunto é sempre algo banal, um som, uma palavra, uma entonação. Percebe-se, também, que as personagens são somente...

...o terreno onde estas coisas insignificantes se instalam... As personagens são uma espécie de barris transparentes onde as reações acontecem... pouco importa quem sejam as personagens. Somente as reações me interessam... ${ }^{8}$

A descoberta dos tropismos por Sarraute a fez deparar-se com a incompreensão dos leitores. Na avaliação inicial de suas primeiras obras, vários críticos disseram que essas eram obscuras, herméticas, difíceis, reservadas a poucos leitores já iniciados, a intelectuais. ${ }^{9}$ Conhecendo as possíveis reações de seus leitores, Nathalie Sarraute antecipa-se: prepara-nos para entrar no texto, mostra-nos os obstáculos, leva-nos por caminhos até então não explorados.

Mas você já está perdendo a paciência, já está pronto para largar tudo isso, já vai jogar tudo isso no lixo [...] não tem nada de interessante lá, nada que mereça ser conservado? Mas você não acha que eu mesmo teria me desfeito disso se fosse tão ruim assim? [...] Então confie um pouco em mim... ${ }^{10}$

O jogo da leitura/representação pode ser surpreendente, emocionante. Consciente do risco de ter seus textos não lidos/representados, as personagens envolvem-nos com suas conversas, transformam-nos em testemunhas, em cúmplices de suas falas. Feito o vínculo com o leitor/espectador, as personagens guiam-nos nos seus universos inquietantes, revelam-nos seus tropismos, matéria-prima na construção de todos os seus

\footnotetext{
${ }^{6}$ BENMUSSA. Nathalie Sarraute, qui êtes-vous?, p.108.

${ }^{7}$ SARRAUTE. Isma, p.21. (Tradução minha.)

${ }^{8} \mathrm{Cf}$. RYKNER. Des tropismes de l'acteur à l'acteur des tropismes, p.15. (Tradução minha.)

${ }^{9}$ IBIDEM. p.9.

${ }^{10}$ Sarraute. Usage de la parole, p.23-24. (Tradução minha.)
} 
textos, e nos fazem mergulhar neles sem que saibamos exatamente para onde vamos: "... É o que eu te ofereço, esta breve incursão, esta divertida excursão, esta excitante impressāo de aventura, de perigo, mas você pode voltar atrás quando quiser..." 11

Mesmo desorientados, já no primeiro momento, porém, sentimos a fascinação desse universo. Algo incomoda-nos, persegue-nos, sensações que já experimentamos, movimentos internos, íntimos, indescritíveis, indizíveis estão ali registrados em palavras. O que é isso? Por quê? De onde isso vem? Você vai saber. Siga-me. ${ }^{12}$ As personagens falam-nos, prendem-nos nas suas redes de palavras e de tropismos para que continuemos a conversar. Esse gesto de fazer e manter o contato, de querer que um outro participe, seja cúmplice e companhia, realiza-se, também, no nível do enredo e é comum a todas as personagens de Nathalie Sarraute: Você aí, minha testemunha... se debruce comigo... vamos juntos ver... ${ }^{13}$ Todos querem conversar, seguir com alguém o trajeto, ver juntos, mostrar, mergulhar na substância amorfa dos tropismos que os coloca em contato ou, ao contrário, os separa.

Em todas as peças de Nathalie Sarraute há sempre alguém que fala a alguém ou a si mesmo. Reconhecer quem é esse eu que fala é, porém, uma tarefa quase impossível. Todos são sujeitos da enunciação. Esses $e \mathfrak{u}$, que "só podem ser identificados pela instância do discurso que os contém e somente por eles", ${ }^{14}$ são quase sempre ambíguos. Não somente a designação desse locutor é freqüentemente escamoteada, mas também aquele que o ouve, o locutário, tem uma existência e uma identidade pouco definidas. Todos se confundem no anonimato dos pronomes.

E é quase sempre no meio de uma multidão, real ou imaginária, que as personagens de Sarraute dizem eu. É significativo ver em cena nove personagens em Le mensonge, sete em Le silence, dez em Isma. Em C'est beau, Elle est là e Pour un oui ou pour un non temos três, quatro e quatro personagens respectivamente, além, é claro, de um grande número de vozes, vizinhos, pessoas de bom senso e de bons costumes que povoam as peças com seus conselhos, suas consciências e boas histórias.

Além disso, Nathalie Sarraute apresenta um dos traços que a definiu como nouvelle-romancière: o sujeito despersonalizado. Un sujeito que começa por perder as características físicas, as relações de parentesco (sempre vagas e incertas), o nome próprio, a autoria dos fatos, até chegar ao limite do desaparecimento, ao vazio da identidade. Basta ver alguns exemplos de nomeações das personagens : F.1, H.3, Ela, Ele, A... isso quando existe alguma didascália que indica nomes.

Sarraute arranca de suas peças as categorias onde a tradição psicologizante encarcerou a personagem. Ela destrói a eterna tentação da caracterização, recusa a personagem travestida de caráter, de totalidade e integridade de ação. As formas

\footnotetext{
"Sarraute. Le Planétatium, p.31. (Traduçāo minha.)

${ }^{12}$ Sarraute citado por Rykner. Des tropismes de l'acteur à l'acteur des tropismes, p.12-13. (Tradução minha.)

${ }^{13}$ SARRAUTE. Entre la vie et la mort, p.174. (Tradução minha.)

${ }^{14} \mathrm{~A}$ respeito da natureza dos pronomes, Benveniste acrescenta: "(...) não há um conceito 'eu' englobando todos os eu que se anunciam a todo instante, na boca de todos os locutores, no sentido em que há um conceito 'árvore' ao qual se reduzem todos os empregos individuais de árvore... " Eu, segundo o autor, é um signo virtual que só é preenchido na instância do discurso. Eu só é Eu na relação que ele entretem com um tu. Cf. Benveniste. Problemas de Lingǘstica Geral, p.277-293.
} 
exteriores e interiores, que constróem as personagens tradicionais e nas quais elas se inscrevem, foram abandonadas. As personagens sarrautianas perdem a credibilidade de persona, já que se aponta a complexidade interna que as animam e as minam. ${ }^{15} \mathrm{O}$ eu passa, então, a ser somente um artifício, uma construção: Mas justamente eu não sou... eu sempre te disse, não há eu. ${ }^{16}$ Para restituir (ou recriar) esse eu naquilo que o "anima e o mina", é necessário renunciar à síntese da psicologia tradicional que aprisiona o sujeito em personagens e tipos. Toda tentativa de teorização é contestada não só por Sarraute, mas também por suas personagens:

Oh não... por favor... chega de complexos. As repressões. As regressões. As fixações infantis... chega disso: o pré-fabricado. O confeccionado. Os clichês. Os terríveis objetos em série (...) Não, por favor não. Eu sei onde você quer chegar. Eu sei onde você quer nos levar... Não nos leve a esse ponto. Nada de transferência. Nada de ciúmes. Nada de complexos de inferioridade. Oh, Senhor, onde eu estava com a cabeça? Não. Tentaram de novo te enganar... ${ }^{17}$

Nathalie Sarraute percebe que não há mais necessidade de explicitar ao leitor quem fala, nem o que se fala, pois o importante, segundo ela, é como se fala e as sensações que a fala provoca. Assim, a personagem não precisa mais de seus atributos físicos, sociais, e mesmo psíquicos.

O locutor só se constitui como sujeito na medida em que fala a um locutário. É somente na relação com o outro que ele pode se definir como sujeito, como eu. ${ }^{18}$ Nos textos de Nathalie Sarraute há um jogo de vozes, de diálogos, com um mesmo objetivo: fazer e manter o contato, dialogar, conversar, dividir as opiniōes, para que se re-tenham as sensações, a sensação de estar vivo, de sentir, de falar. É preciso assegurar-se de que não se está só. O outro se torna, assim, um elemento vital. Ávido de preencher o vazio da identidade, o sujeito procura o outro, sua presença, sua aprovação: “... Será possível que você não sente como eu [...] Você também não sente?..." ${ }^{19}$ Em Elle est là, a personagem $\mathrm{H} .2$ se surpreende com o comportamento de sua colaboradora F., que se recusava a se exprimir e se refugiava em um mutismo defensivo:

H.2: Oh nada. Nada, justamente, você não fez nada. Não disse nada.

Você se cala.

F.: Eu tinha que falar?

H.2: Claro, teria sido muito melhor. ${ }^{20}$

\footnotetext{
${ }^{15}$ Segundo Rykner, depois de Joyce, Proust e Virginia Woolf, a personagem perdeu sua qualidade de ser acabada, uma vez que se apontou sua complexidade interna paradoxal. Oeu do romance do século XIX é uma construção abstrata, simplificadora e totalizante de uma pluralidade de eu. Para restituir ou recriar o eu, é necessário renunciar à síntese destruidora da psicologia tradicional e às combinaçōes herdadas da narrativa clássica que garantiam sua integridade fictícia. Essa renúncia orientará os novos modos de criação das personagens, e os mesmos recursos utilizados para animá-las irão miná-las. Cf. RYKNER. Des tropismes de l'acteur à l'acteur des tropismes, p.67-72.

${ }^{16}$ SaRraUte. Disente les Imbéciles, p. 68. (Tradução minha.)

${ }^{17}$ SARRAUTE. Isma, p.78. (Traduçāo minha.)

${ }^{18}$ Benveniste diz: "(...) tu é o sujeito alocutado na presente instância do discurso contendo a instância lingüística eu." [...] "Assim, os indicadores eu e tu não podem existir como signos virtuais, eles existem somente enquanto que atualizados na instância do discurso, onde eles marcam por suas próprias instâncias o processo de apropriação pelo locutor." Cf. BENVENISTE. Problemas de Lingǘstica Geral, p.279-281.

19 SARRAUte. Usage de la parole, p.111-114. (Tradução minha.)

${ }^{20}$ SarRaUtE. Elle est là, p. 16. (Tradução minha.)
} 
Esse movimento de pulsação em direção ao outro visa produzir uma compreensão mútua das sensaçōes e dos tropismos. É a partir da relação complexa, móvel, plena de ambivalência - amor-ódio, adesão-ruptura — que uma personagem mantém com a outra que Sarraute compõe a intriga linguageira, sem açāo, só de choque de palavras. Essa relação se dá em duas formas de diálogo, que a própria escritora designa como conversação e sub-conversação, ${ }^{21}$ colocando em cena dois mundos: o exterior, dos gestos, das palavras: a conversaçāo; e o interior, das reflexōes, dos movimentos íntimos: a subconversação. A conversação é o diálogo que o sujeito mantém realmente com o outro. A sub-conversação aproxima-se do monólogo interior, é aquilo que se desenvolve no segredo da consciência, no imaginário, de onde quase sempre os tropismos emergem. Aquele que diz eu em suas peças é o sujeito que procura e foge dos tropismos.

Em Tropismes, sua primeira obra, Nathalie Sarraute deu-se conta de uma nova realidade, de alguma coisa que permanece invisível e que se revela, a cada obra, em nova forma, sua matéria-prima. Com grande obstinação, a escritora pesquisa os tropismos, movimentos que se propagam no e do mais profundo de uma zona interior neutra. Movimentos que não estão sob o controle das personagens c que são produzidos, ora por uma excitação externa, palavra ou expressão, a presença de outra personagem, objetos ou cenas, ora por algo que permaneceu na memória e que surge, involuntariamente. Esses movimentos e sensações, impossíveis de serem analisados, são revividos, apresentados e exteriorizados por meio da palavra. Os tropismos são correntes de vida que fazem vibrar as palavras, tornando-as capazes de captar e reter as sensaçōes invisíveis. É pelas vibrações da linguagem que Sarraute descobre o trabalho da escritura como pura atividade sensível, como puro fenômeno de vida. Escritura realizada na tensão do próprio viver e sentir, e no desejo de manter, na palavra, a sensação, pura e instantânea.

A originalidade de Sarraute sustenta-se, entāo, na relação construída pelos tropismos, entre sensações e linguagem. Em conversa com Benmussa, a escritora declara que essa combinaçāo dá-se quando

(...) aparentemente não há nada $[. .$.$] o que se passa por traz dessas palavras inofensivas$ é realmente o equivalente, se se pode dizer, a um roubo, a uma agressão muito forte. E é assim em todas as minhas peças de teatro e em meus romances. O que aconteceu? Não aconteceu nada. ${ }^{22}$

Escrever é, então, uma forma de inventar e reviver as sensaçōes, dar-lhes vida, pois onde, aparentemente, não há nada, não acontece nada, algo de ignorado, em outro plano, começa a acontecer. Algo de insignificante em sua aparência exterior transforma-se num território sensível, irresistível, de extrema importância e que será catalisado pela linguagem. ${ }^{23}$

\footnotetext{
"SARRaute citado por Benmussa. Nathalie Sarraute, qui êtes-vous?, p.58.

${ }^{22}$ Benmussa. Nathalie Sarraute, qui êtes-vous?, p. 14. (Tradução minha.)

${ }^{23} \mathrm{Com}$ relação à linguagem que quer preservar a emoção, Artaud acrescenta: (...) Il faut bien admettre même au point de vue de l'Occident que la parole s'est ossifiée, que les mots, que tous les mots sont gelés, sont engoncés dans leur signification, dans une terminologie schématique et restreinte. ARTAUD. Le théâtre et son double, p.183.
} 
A palavra, a linguagem torna-se de tal forma o centro das atenções que ela se constitui a própria matéria do drama, como Pour un oui ou pour un non:

H.1: E então eu teria dito a você: "É exatamente isso?"

H.2: Não exatamente dessa forma... tinha entre "É exatamente" e "isso" um intervalo maior "É exatameeeennte.......isso....." Um acento maior sobre o "exatamente" um alongamento:

"exatameeennte..." e uma pausa antes do "isso" acontece... não é por acaso. ${ }^{24}$

Indo além de seu papel de informar e comunicar, a linguagem deve fazer experimentar uma certa ordem de sensações, enformar — dar forma. As significações só se realizam na medida em que são carregadas de sensações. São as sensações que especificam a linguagem em seu caráter literário. A linguagem só é essencial quando exprime uma sensação, não importa qual. ${ }^{25}$

Para que a linguagem se adapte à sensação, lhe dê vida, é necessário, ainda, que essa sensação seja viva, isto é, que seja uma sensação nova, direta, espontânea, e nāo expressa centenas de vezes; pois as sensações já conhecidas, que já foram objeto de expressão literária, são formas convencionais, já fixadas, que perderam a fluidez, a leveza e a força de expressão, o poder de sugestão, a singularidade, o frescor. Também as idéias devem ser sensíveis, senão a linguagem torna-se bruta, ossificada, não literária.

Para permitir que essas qualidades se manifestem, é necessário que a linguagem produza uma sensação nova, ainda desconhecida. É o que afirma Sarraute em entrevista:

A única coisa que eu tenho certeza é da sinceridade do meu esforço para extrair uma sensação que me parecia nunca antes expressa, para retirá-la daquilo que a encobre e tentar fazê-la viver através da linguagem. ${ }^{26}$

Assim, essa sensação ainda desconhecida adquire uma qualidade particular: ela é construída pela linguagem, funde-se com a linguagem, faz-se linguagem. Essa fusão da linguagem e da sensação intacta cria alguma coisa de particular — os tropismos -, que tem existência própria. As palavras perdem sua significação comum: são portadoras de sensações. E, por sua vez, as sensações dão vida às palavras, tornando-as especiais. A fusão é total, sem falhas. A linguagem tomada pela sensação inicial cria uma sensação nova, que é da ordem puramente literária.

Em todas as suas peças, a mesma ilustração dos tropismos. Trata-se de mostrar o efeito, o mal-estar, produzido por um certo silêncio. ${ }^{27}$ Pode ser uma mentira insignificante, uma certa maneira de pronunciar palavras terminadas em -isma, ou expressões do tipo está bem... por um sim ou por um não... ela está aí... (todas títulos de suas obras). Tudo nasce a partir de "idéias" na cabeça de alguma personagem, que aparecem como uma ameaça ou uma espera insuportável. É a partir desses dramas microscópicos

\footnotetext{
${ }^{24}$ SARRAUTE. Pour un oui ou pour un non, p.13-14. (Tradução minha.)

${ }^{25}$ BENMUSSA. Nathalie Sartaute, qui êtes-vous?, p.191.

${ }^{26}$ IBIDEM. p.194. (Tradução minha.)

${ }^{27}$ A respeito das pausas em um diálogo, Calin diz: Dans l'espace qui sépare une question d'une réponse, une constatation de son commentaire, ils incorporent des scènes qui ont parfois duré de longues heures. Ils opposent à la sécheresse des mots prononcés l'extraordinaire foisonnement d'une pensée inexprimée qui allie en un même jaillissement sensations et raisonnements, passé et présent, dialogues et images. Cf. CALIN. La vie retrouvée, p.52.
} 
da vida cotidiana que se desenvolve toda a ação dramática, "em um diálogo mais condensado, mais denso, mais tenso e mais excitante". ${ }^{28}$

Desde Tropismes, sua primeira obra, Nathalie Sarraute dedica-se a explorar os tropismos, nomeados por ela de matéria psicológica. Eles definem o nível da consciência das personagens, no limite da subconsciência. Esse nível específico de consciência é o território dos tropismos que, substituindo a intriga romanesca, se aproxima do território da ação dramática.

De obra em obra, Sarraute demarca melhor o território dos tropismos, tornando seus limites mais precisos. Após a delimitação segura desse território, ela amplia as situações tropismais - articuladas às sensações - até que essas alcancem maiores vastidões e complexidades. Sua técnica tornar-se-á, a cada obra, mais refinada e desenvolvida, permitindo-lhe abandonar as ações encadeadas e articular os elementos da narrativa em torno dos tropismos.

Cada peça se organiza a partir de variações de um tema, um objeto, uma personagem, entre outros elementos da escritura. Independentemente daquilo em torno do qual os tropismos se organizam, a ação dramática desencadeada por eles será sintetizada por certas palavras, até chegar ao ponto em que são elas os próprios tropismos, como por exemplo a expressão "Está bem" na peça Pour un oui ou pour un non.

Em Le silence (1964) os tropismos, as sub-conversaçōes e os diálogos surgem a partir de um certo silêncio. Atraídas e excitadas por este silêncio, as personagens constróem o diálogo. Elas começam a falar, a se agitar, a se debater:

Mas você, eu sempre senti isso... as palavras para você... Você nunca disse nada sem importância. Nunca, nada de vago, de pretensioso. Claro, você deve se valer das palavras de vez em quando. Isso é bom. Para viver. Um mínimo. Uma palavra, você sabe melhor que ninguém, é grave. ${ }^{29}$

Le mensonge (1966) é construída a partir de uma mentira "em estado puro" que não afeta em nada a nossa vida. É uma espécie de contra-verdade dita por alguém que nos é indiferente:

Jacques: Primeiramente não comece por chamar isso de verdade. Mude o nome. um nome, desde que alguém o pronuncie, que impressiona. A gente fica preso a isso como se nossa vida dependesse disso ... A gente se vê obrigado... É preciso mudar isso... Vamos chamá-lo de mentira... ${ }^{30}$

C'est beau (1975) é composta por três personagens, um casal e seu filho, que experimentam uma sensação que faz com que, em presença de outras pessoas, elas não degustam, não sentem o prazer de uma música ou de uma pintura. Este casal, na presença do filho, não pode dizer "Está bem":

Ela: Se eu me atrevo, veja você: "Está bem". Eu posso até mesmo te mostrar. Eu o exponho... veja, olhe para mim. Eu te digo — você percebe? - Está bem... Eu te pergunto: Você não acha?

\footnotetext{
${ }^{28}$ Benmussa. Nathalie Sarraute, qui êtes-vous?, p. 164. (Tradução minha.)

${ }^{29}$ Sarraute. Le Silence, p.57. (Tradução minha.)

${ }^{30}$ SARRAUTE. Le Mensonge, p.137. (Tradução minha.)
} 
O Filho, exitante: É que... esta expressão "Está bem"... isso acaba comigo... basta alguém dizer isso em qualquer situação e logo... tudo muda, tudo muda..."

Elle est là (1980) é uma defesa da liberdade de pensar. Pode-se estar a favor da personagem feminina ou contra ela quando há uma recusa em discutir, visto que as idéias devem ser debatidas livremente...

É engraçado, agora eu acho que começo, pela primeira vez, a entender (...) ela se solta, se liberta, rompe o lacre, ela se livra, ela, a verdade, ela própria... a verdade... somente ela... por sua única e exclusiva existência é a mestra... tudo em torno dela, docilmente, nada the resiste... tudo em torno dela se sucumbe... ela ilumina... (luz baixa)... que clareza... que ordem (...) ela se libera, ela se expande... ela ilumina... (luz baixa)... ${ }^{32}$

Pour un oui ou pour un non (1982) é um trabalho de pesquisa sobre o "re-sentido " e também e a maneira como exprimi-lo exteriormente, através da entonação. Algo de ínfimo, uma entonação, que é interpretada por alguém e daí advém um drama interior. Dito de outra forma, é uma interpretação do que é dito e como é dito, o que isso esconde e o que isso revela:

H.1: É o caso de dizer: por um sim ou por um não...Porque eu já disse: "É exatamente isso" ... Oh desculpe, eu não pronunciei como se deve: "É exatameeennte... isso..."33

Em suas peças, o conflito entre a sensação e a palavra é contínuo. Há uma luta entre a sensação, que é preciso conservar tal qual ela é, e, ao mesmo tempo, concretizála em palavras que a deformam. A força da palavra procura destruir a sensação e vice-versa. A partir do momento em que a sensação é concretizada em palavras, ela deixa de ser o que era para ser outra coisa: já é o tropismo, um tecido que encobre e, porque encobre, revela os contornos daquilo que tenta esconder.

Suas peças são, no final das contas, a imagem de um objeto inominável - a experiência tropismal - ao qual nenhuma linguagem consegue aderir mas que se deixa, paradoxalmente, fiar-se em palavras. As peças parecem oscilar entre o desejo de ruptura com a linguagem para alcançar a pura sensação, e a consciência de que isso só é alcançado pela linguagem. O teatro de Sarraute é a tentação de exterminar a palavra e, ao mesmo tempo, the ser fiel para possibilitar a construção tropismal.

\footnotetext{
${ }^{31}$ SARRAUTE. C'est beau, p.81. (Tradução minha.)

${ }^{32}$ SARRAUTE. Elle est là, p.58-59. (Tradução minha.)

${ }^{33}$ SARraUte. Pour un oui ou pour un non, p.13. (Tradução minha.)
} 


\section{RÉ S U M É}

Ce texte a pour but l'étude du théâtre de Narhalie Sarraute où sont analysés deux aspects singuliers de son écriture: la présence des sujets fragmentés qui s'exhibent dans une structure dramatique, et la recherche de ce qu'elle a nomé tropismes.

\section{MOTS-CLÉS}

théâtre, Nathalie Sarraute, tropismes, Nouveau Roman

\section{REFERÊNCIAS BIBLIOGRÁFICAS}

AlBÈRES, René-Marill. Le roman aujourd'hui: 1960-1970. Paris: Albin Michel, 1970.

ArTaud, Antonin. Le théâtrhe et son double.Paris: Gallimard, 1983. Idées, 114.

Benmussa, Simone. Nathalie Sarraute, qui êtes-vous? (conversations avec Simone Benmussa).

Lyon: La Manufacture, 1987.

Benveniste, Émile. Problemas de Lingüística Geral. Trad. Maria da Glória Novak e Luiza Neri. São Paulo: Companhia Editora Nacional, 1976.

Calin, Françoise. La vie retrouvée, étude de l'oeuvre romanesque de Nathalie Sarraute. Paris: Minard, 1976.

Goldmais, Lucien. Pour une sociologie du roman. F ris: Gallimard, 1964. 229p.

JANVIER, Ludovic. Une parole exigeante. Paris: Minuit, 1964. 188p.

Perrone-Moisés, Leyla. O novo romance francês. São Paulo: São Paulo, 1966. 161p. (Coleção Buriti, 13)

RYKNer, Arnaud. Des tropismes de l'acteur à l'acteur des tropismes. Revue des Sciences Humaines. Lille, n.217, p.139-147, 1990-1.

Sarraute, Nathalie. Disent les imbéciles. (Romance.) Paris: Gallimard, 1984.

Sarraute, Nathalie. Elle est là suivi de C'est beau. (Teatro.) Paris: Gallimard, 1978.

Sarraute, Nathalie. Isma. (Teatro.) Paris: Gallimard, 1970.

Sarraute, Nathalie. L'Ere du Soupçon; essais sur le Roman. (Ensaio.) Paris: Gallimard, 1956. Sarraute, Nathalie. L'usage de la parole. (Romance.) Paris: Gallimard, 1983.

Sarraute, Nathalie. Le silence suivi de Le mensonge. (Teat!n.) Paris: Gallimard, 1978.

Sarraute, Nathalie. Portrait d'un inconnu. (Romance.) Paris: Gallimard, 1983.

Sarraute, Nathalie. Pour un oui et pour un non. (Teatro.) Paris: Gallimard, 1982.

Sarraute, Nathalie. Tropismes. (Romance.) Paris: Ed. de Minuit, 1957.

Ricardou, Jean. Nouveau roman, tel quel. Poétique, Paris, n.4, p.433-54, 1970.

Ricardou, Jean. Pour une théorie du nouveau roman. Paris: Seuil, 1971.

Ricardou, Jean. Problèmes du nouveau roman. Paris: Seuil, 1967. 